\title{
Monetary Policy and Asset Price Interactions in India: Should Financial Stability Concerns from Asset Prices be Addressed Through Monetary Policy?
}

\author{
Bhupal Singh \\ Reserve Bank of India \\ Sitikantha Pattanaik \\ Reserve Bank of India
}

\begin{abstract}
The dynamic interactions between monetary policy and asset prices have conventionally been examined in terms of the asset price channel of transmission of monetary policy, given the pre-crisis analytical consensus against the use of monetary policy to respond directly to asset price inflation. In the post sub-prime crisis period, however, there has been an overwhelming intellectual support for revisiting the issue of whether monetary policy should become more sensitive to asset price trends and respond proactively to prevent any build up of bubbles. In the Indian context, this paper provides empirical evidence to explain the relevance of a policy of no direct use of the interest rate instrument for stabilising asset price cycles. While the asset price channel of monetary policy is clearly visible in empirical estimates, there is no evidence of monetary policy responding to asset price developments directly. Asset price changes also do not seem to influence the inflation path, as per the impulse response analysis in a structural VAR model. This suggests why monetary policy may continue to refrain from responding directly to asset price cycles. Credit market shocks, however, explain significant

\footnotetext{
*Corresponding address: Bhupal Singh; Reserve Bank of India (RBI), Department of Economic and Policy Research(DEPR), Central Office, Saheed Bhagat Singh Road, Fort Mumbai, India. / Sitikantha Pattanaik; Reserve Bank of India (RBI), Department of Economic and Policy Research(DEPR), Central Office, Saheed Bhagat Singh Road, Fort Mumbai, India. E-mail : spattanaik@rbi.org.in. ○2012-Center for Economic Integration, Sejong Institution, Sejong University, All Rights Reserved.
} 
proportion of asset price variations over medium to long run, which though could be part of a broader comovement of variables over the business cycle, as visible in terms of simultaneous movement in real activity, credit flows and asset prices. Higher interest rates seem to lead to contraction in output, credit demand as well as asset prices; hence, only the impact on asset prices should not be viewed as a good enough reason to use monetary policy for stabilising asset price cycles. The financial stability concerns from asset price bubbles could be better addressed through micro and macro-prudential measures, and the effectiveness of such measures could be enhanced when implemented in a sound macroeconomic policy environment.

- JEL Classification: C33, E52

- Keywords: Monetary Policy, Asset Prices, VAR Model

\section{Introduction}

The price stability objective pursued by the central banks is generally defined in a manner that excludes asset prices. Asset price is often viewed by the central banks as another macroeconomic variable which could potentially influence the inflation path either by impacting inflation expectations, or through the wealth effect on aggregate demand, or by altering the cost of funds. The relationship between monetary policy and asset prices has been conventionally analysed through the asset price channel of monetary policy transmission, under which asset prices respond to monetary policy changes and thereby may impact the ultimate policy goals relating to inflation and output. The pre-crisis mainstream view on why a central bank should not directly aimed at containing asset price inflation was premised on certain sound arguments: (a) bubbles are hard to differentiate from genuine bull runs, and central banks have no comparative advantage over the markets to come to any credible conclusion on the fundamental value of assets, (b) monetary policy instruments could be ineffective in preventing asset bubbles, particularly speculative bubbles, as the magnitude of the increase in interest rates would have to be large enough to be able to prick a bubble, which in turn would entail large loss of output, and (c) central banks have no mandate on asset prices. As a result, the pre-crisis emphasis in monetary policy strategies was to manage the impact of asset price developments on inflation and growth, whether in a forward looking manner by anticipating the impact on the inflation outlook, or by reacting to 
the impact on output and inflation when it becomes visible after the bubble bursts.

The emerging perception after the global crisis is that central banks can contribute to preventing the build up of asset bubbles by: (a) avoiding credit bubbles, persistent excess liquidity conditions and build up of leveraged positions in asset markets, and (b) using prudential regulation in terms of counter cyclical provisioning, counter cyclical risk weights for capital requirement, limiting the maximum exposure of banks to sensitive assets and prescribing margin requirements (or loan to value ratio). While the former falls in the domain of monetary policy, the latter belongs to the purview of financial regulation. The focus of this paper is on what monetary policy per se could do about asset price inflation, rather than whether a central bank could use instruments other than the interest rate to stabilise asset price cycle. Against this background, Section II of the paper presents the academic debate on the role of monetary policy in relation to asset prices, with a review of literature that reflects the pre-crisis consensus view as well as the lack of consensus after the global crisis. The issue of whether monetary policy should be assigned any role relating to asset prices in India has been evaluated through various empirical tests for India in Section III, not withstanding data limitations in conducting empirical research involving housing assets in India. Concluding observations are outlined in Section IV.

\section{Monetary Policy and Asset Prices - the Debate}

Monetary policy actions could get transmitted through changes in financial prices (e.g. interest rates, exchange rates and asset prices) and financial quantities (e.g. money supply and credit aggregates), which in turn may influence the ultimate goal variables, namely inflation and output. The reverse causation may also be significant since monetary policy actions are often based on feedbacks received from the lead indicators of macro-financial conditions, given that monetary policy has to be forward looking, recognising the long and variable lags.

In this expected bi-directional causality in the interactions between monetary policy and asset prices, clarity on the role of monetary policy with respect to asset prices becomes important. In the first type of causation running from monetary policy action, asset prices may change, but the objective of policy change could be to attain the ultimate goals relating to inflation or output. Any asset price changes that may take place in this process would be just coincidental, not intentional. Once monetary policy actions intentionally start targeting asset prices it could necessarily 
involve sacrifice of growth and inflation objectives. That is because the magnitude of the increase in interest rate would have to be large enough to effectively pop an asset price bubbles. If that happens, output could contract and deflation fears could creep in. Thus, all objectives of monetary policy, i.e., not only those relating to output and inflation, but also financial stability could get sacrificed.

The second type of causation, which could be seen in terms of an interest rate policy rule function, largely remains hypothetical, since following the pre-crisis consensus, no direct feedback from asset prices seems to have triggered any change in policy interest rates of any major central bank. Asset prices may only indirectly condition an interest rate action, through the impact on output and inflation, for which the wealth and income effects of asset price changes would have to be significant.

After the global crisis, those who proposed a "lean against the wind" role for monetary policy seem to suggest a place for asset prices directly in the interest rate policy rule function. Since credit bubbles and excessive leverage could be the driving forces behind asset price bubbles, either asset prices directly or credit and leverage as lead indicators of asset prices would then have to find explicit place in the monetary policy reaction function. This is premised on two broad arguments: (i) Given the endogenous money supply process, in which money and credit growth may be largely demand driven, central banks could change the credit conditions or discourage excessive leverage only by changing the interest rates. Use of macro-prudential measures or sector specific credit/prudential policies could attain the goal, but these are not monetary policy measures. Hence, any role for monetary policy should be seen only through the interest rate rule, where interest rate would respond directly to asset price trends; (ii) Taking a view on asset price bubble or credit bubble should not be difficult for a central bank, since they in any case take views on "potential output" and "threshold inflation" for changing their policy interest rates, and such estimates are not free of errors. Only the extent of error in judgement could be higher for asset prices or credit bubbles, compared to errors in estimating potential output and threshold inflation. Moreover, if central banks can use macro-prudential regulation, they have to take a view on the extent of misalignment in asset prices, to be able to alter the risk weights for capital adequacy purpose or assign specific provisioning requirements in proportion to the extent of risk expected from exposures to asset price volatility. Thus, the pre-crisis presumption that asset bubbles are hard to identify might have helped central banks to avoid any use of interest rate instrument in pursuit of asset price objective, but 
given the overwhelming emerging support for use of macro-prudential regulation to promote systemic financial stability, specific views would have to be taken by the central banks on asset prices. The dominant remaining argument against the use of interest rate instrument, then, would have to be based on the bluntness of the instrument, which can limit the asset prices from growing into a bubble only at the expense of sacrificing output and inflation objectives.

Thus, for use of macro-prudential regulation, a central bank may have to necessarily take a view on asset prices, but this assessment need not feed into decisions on changes in policy interest rates. A Central Bank empowered with the instrument of macro-prudential regulation may start "leaning against the wind" but in pursuing this objective, the interest rate instrument may still have no role to play. Thus, the pre-crisis consensus may still be relevant after the global crisis, even though convincing counter arguments have been expressed, some of which are mentioned in the review of literature.

\section{A. Review of the literature}

Theoretical and empirical research appears more divided after the global crisis on the issue of role of monetary policy relating to asset price developments. A rich body of literature prior to the global crisis seemed to support the argument that a monetary policy approach which responds primarily to the inflation and aggregate demand outlook rather than directly trying to prick the bubble is likely to yield better macroeconomic outcomes (Bernanke, Gertler and Gilchrist, 1999; Bernanke and Gertler, 2001; Gruen, Plumb and Stone, 2005). The pre-crisis consensus reflected the famous Greenspan orthodoxy on asset price build-up that argues that it is hard to identify bubbles ex ante and central banks may not have better information than markets to influence asset prices. ${ }^{1}$ Further, even if a bubble can be identified ex ante, using the interest rate is ineffective in bursting a bubble. ${ }^{2}$ Similarly, monetary policy response to tackle an asset boom can interfere with the role of asset prices in allocating resources, particularly if there is uncertainty with regard to the presence and nature of a bubble. The asset bubbles are broadly explained as asset prices rising above the level warranted by economic

\footnotetext{
${ }^{1}$ Bernanke and Gertler (2001) argued that central banks should disregard asset prices in their policy formulation. They found little, if any, additional gains from allowing an independent response of central bank policy to the level of asset prices.

${ }^{2}$ Mishkin (2008) opined that since it is difficult to identify asset price bubbles with certainty, any monetary policy response to misidentified bubbles may hamper the growth process.
} 
fundamentals, as measured by the discounted stream of expected future cash flows that will accrue to the owner of the asset. ${ }^{3}$ The difficulties in identifying asset price bubbles arise mainly from two factors: first, private agents' subjective expectations are the key determinant of asset prices, particularly in the short run, posing difficulties in disentangling the purely psychological component from the objective valuation of the asset; second, asset bubbles often arise from overreactions to news about fundamentals. ${ }^{4}$

Given the difficulties in identifying asset price bubbles, the best course for monetary policy could be to cushion the adverse impact once the bubble bursts (Bean, 2003; Bernanke and Gertler, 1999, 2001; Blinder and Reis, 2005; Bordo et al., 2002, 2003; Bordo and Wheelock, 2004, Filardo, 2004; Greenspan, 2002; Roubini, 2006). For equity prices to be a useful monetary policy indicator, a credible relationship between changes in monetary policy and changes in equity prices as well as between changes in equity prices and changes in inflation should be established (Saxton, 2003). Empirical investigations, however, do not seem to offer a reliable relationship between changes in monetary policy and equity prices. Mishkin and White (2002) argued that most fluctuations in stock prices occur for reasons not associated with monetary policy, either reflecting real fundamentals or animal spirits. The loose link between monetary policy and stock prices, therefore, implies the limited ability of central banks to control stock prices. Similarly, there does not seem to be a reliable positive empirical relationship between changes in equity prices and changes in general price levels (Filardo, 2000; Goodhart and Hofmann, 2000; Stock and Watson, 2001; Tatom, 2002). Moreover, the consumption and investment sensitivity to the wealth effect of equity and housing prices, despite their growing share in the household wealth and the economy, may be relatively weak (Gramlich, 2001; Kuttner and Mosser, 2002; Ludvigson and Lettau, 2002).

\footnotetext{
${ }^{3}$ Key features of asset prices that are associated with bubbles could be best analysed in the framework of forward looking general equilibrium models with the assumptions of rational behaviour and infinite horizons. Thus, the rational bubbles reflect expectations of rising prices that can lead to self-fulfilling equilibrium outcomes, with the following expectational restriction (Filardo, 2004): $\mathrm{E}_{t} \Omega_{t}+1=\lambda \Omega_{t}, \lambda \square 1$. The rational asset bubbles tend to develop without link to fundamentals since the holders of speculative asset experiencing bubbles are also guided by the expectation of persistent rise in the price of that asset. Such bubbles are identified as generating significant persistent overvaluation or undervaluation of asset prices due to excessive reaction to fundamentals (Froot and Obsfeld, 1991).

${ }^{4}$ The difficulties involved are extracting information from a constellation of asset prices, which would require disentangling risk premia from expectations component, identifying relevant state variables that enter the asset pricing and determining the functional form of the pricing relationship (Hordahl and Packer, 2007).
} 
After the global crisis, influential opinions have supported the need for making central banks more sensitive to asset price developments in the conduct of their monetary policies, even though justifications for the relevance of the pre-crisis approach also continue to be significant. There was a "lean against the wind" perspective even before the global crisis, which argued that central banks should explicitly respond to perceived asset price bubbles, even if that involves short run deviations of monetary policy from the path conditioned by the inflation-growth objectives (Bordo and Jeane, 2002; Borio and Lowe, 2002; Cecchetti et al, 2000; Crockett, 2001; Detken and Smets, 2004; Filardo, 2000; Roubini, 2006). It was also observed that monetary policy could identify the bubble component from the fundamental component in asset prices and the optimal monetary policy could react more to the bubble than to the fundamental component of asset prices (Rudebusch, 2005). ${ }^{5}$

The pre-crisis perception of the best practice in monetary policy framework as the one characterised by a single target (i.e., price stability) and a single instrument (i.e., short-term policy interest rate) has generally been questioned on the ground that a less inflation-centric and more asset price sensitive monetary policy could possibly have been more appropriate as a crisis preventive mechanism. Even though sustained easy monetary conditions have been highlighted as a causative factor behind the asset price bubbles, empirical estimates suggest that the stance of monetary policy has not generally been a good leading indicator of future busts in asset prices. "...loose monetary policy was not the main, systematic cause of the boom and consequent bust" (IMF, WEO, 2009).

One of the key arguments in the debate on the dynamics between monetary policy and asset prices has been that monetary policy should respond to asset prices only to the extent of their impact on growth, employment and inflation, which are the core objectives of monetary policy (Kohn, 2008). This requires an understanding of how asset prices influence inflation and economic activity. Some have argued that the impact of asset prices on aggregate demand and inflation should fall within the domain of monetary policy. But this perspective is not new, and was known to central banks even before the crisis. Another area that has been argued to fall in the domain of monetary policy is the asset price bubble that may be fuelled by excessive credit growth. The feedback loop between credit growth

\footnotetext{
${ }^{5}$ At the same time, it was viewed that mere escalation of asset price may be an insufficient indicator of asset price bubbles.
} 
and asset price growth could potentially pose challenges for the inflation and growth objectives of central banks. Hence, it is argued that monetary policy should respond to asset price bubbles that are propagated by excessive credit expansion in the economy (Blinder, 2008). Another argument is that asset price bubbles can have serious adverse macroeconomic consequences and therefore, it is preferable to try to eliminate the source of macroeconomic instability directly by adopting a policy of leaning against the wind. Since central banks are generally held responsible for financial stability even without any explicit mandate, they should monitor asset prices and try to prevent the emergence of bubbles (that invariably lead to financial crashes). ${ }^{6}$ Interest rate could be an effective tool in preventing bubbles (Orphanides, 2010; Papademos, 2009).

From a pragmatic policy perspective, however, it is still largely ambiguous as to how monetary policy could respond to asset prices directly, even if it is presumed that it must in some way. Trichet (2009) noted that “...central banks should not target, nor react mechanically to asset prices. Judgement is necessary in addressing asset price dynamics within an overall framework geared to price stability." Donald Kohn (2008) viewed that "...I am not convinced that the events of the past few years and the current crisis demonstrate that central banks should switch to trying to check speculative activity through tighter monetary policy whenever they perceive a bubble forming...the case for extra action still remains questionable." There is also a lack of political mandate for central banks to control asset prices. With no instrument to target successfully asset prices, by pricking a bubble, a central bank can also create macroeconomic instability and ruin its credibility (Issing, 2009). Whether any specific mandate on asset prices for central banks could undermine central bank independence is an issue which has not been examined very seriously as yet, but the risk to independence cannot be ruled out given that there will be some interest groups that may benefit from asset price inflation, whether genuine or speculative.

Given the inherent practical limitations of monetary policy in dealing with asset prices, other policies that could be effective in ensuring financial stability include regulatory policies and the fiscal policy. ${ }^{7}$ The regulatory policy instruments to deal

\footnotetext{
${ }^{6}$ Excessively accommodative monetary policy may not be immediately reflected in consumer prices given the existence of nominal rigidities in the economy, and hence may be first visible in the asset price increases.

${ }^{7}$ Importantly, in case of housing market, given the transmission lags of monetary policy, interest rate increases are unlikely to be effective in the short run, therefore, special regulatory measures could be more effective (Savoir and Bangui, 2006).
} 
with asset bubbles may comprise limits on the credit exposure to real estate and stock markets, enhancement of relative risk weights/provisioning for bank lending, monitoring of banks' investment in asset markets through special purpose vehicles, counter-cyclical loan to value limits, caps on leverage, and tighter eligibility and collateral requirements on loans for investment in particular assets. Fiscal policy can also work as a countercyclical tool to influence asset price movements through countercyclical public expenditure plans and also suitable adjustment of taxes/ tax exemptions that could influence asset prices. Changes in tax incentives to the real estate sector or investments in financial instruments such as mutual funds and equity over long-term that alters effective return on such instruments may help in containing excessive asset price growth. Use of transaction tax on assets where there is excessive speculation, including Tobin-type taxes when speculative foreign capital inflows are perceived to lead to destabilising growth in asset prices have also been advocated. ${ }^{8}$ As marginal changes in interest rates cannot have much influence on asset prices, particularly when the expected returns on stock/housing assets significantly exceed the cost of borrowed funds, sector specific prudential policies could be more appropriate.

\section{Monetary Policy and Asset Price Dynamics in India}

The empirical assessment for India focuses on the interactions between monetary policy and housing and stock prices. Equity and housing prices have the tendency to be procyclical in nature, as high growth phases are generally associated with an underpricing of risk (Barsky and DeLong, 1993). Four specific issues empirically examined are: (a) whether asset prices exhibit any causal influence on the interest rates, which would be relevant to explain whether monetary policy has responded directly to asset prices in India; (b) whether asset price changes significantly alter the inflation path - which could be important to examine the relevance of an indirect role for monetary policy given the extent to which current asset price trends may alter the inflation outlook; (c) whether interest rate changes lead to expected changes in stock prices alone or also give rise to changes in output and credit demand, which would be important to examine the potential adverse effects of a hypothetical direct use of monetary policy to deal with asset price

\footnotetext{
${ }^{8}$ The literature, however, highlights that the long run effectiveness of such transactions taxes is limited. Even in the short run, the effectiveness of such measures could be circumvented.
} 
Table 1. Causal relationship between interest rate changes in stock prices.

\begin{tabular}{lcc}
\hline Null Hypothesis & F-Statistic & Prob. \\
\hline Yield on 91-day TBs do not Granger cause change in stock prices & 3.51 & 0.03 \\
Change in stock prices do not Granger cause yield on 91-day TBs & 1.93 & 0.15 \\
Yield on 10-year government bonds do not Granger cause change in stock prices & 3.56 & 0.03 \\
Change in stock prices do not Granger cause yield on 10-year government bonds & 0.49 & 0.61 \\
\hline
\end{tabular}

inflation; and (d) whether the relationship between interest rate changes and asset prices could be ambiguous because of the presence of other common factors which may exhibit strong co-movement with both interest rate and asset prices.

\section{A. Monetary policy and asset price cycles}

With the short-term interest rate emerging as the predominant instrument of monetary policy, the interest rate channel of transmission has received significant research focus, even though both asset price and exchange rate channels have become increasingly relevant. A Granger causality analysis of movement in interest rates and changes in stock prices in India for the period 1994:4 to 2010:6 reveals that while interest rate movements cause changes in stock prices, the reverse causation does not hold (Table 1). This seems to suggest that monetary policy does not respond to stock prices, though stock prices respond to monetary policy shocks.

The literature also highlights the possible presence of feedback loops between asset price bubbles and excessive growth in bank credit. ${ }^{9}$ Unlike stocks, real estate, i.e., both residential and commercial, may have a significant credit component. It is often viewed that if asset bubbles are fuelled by expansion in bank credit, then monetary policy should have a role to "lean against the wind". In this case also, credit growth may be an endogenous process, and unless a central bank has at its disposal the authority to directly alter the flow of credit to a specific sector, it may have to resort to the interest rate instrument. The policy of using a macroeconomic tool such as interest rate to address a problem specific to a particular sector may not be appropriate, as it may have adverse consequences for other sectors. In India, however, the Reserve Bank has used in the past its sector specific prudential credit policy measures. Hence, if credit is seen as a causative factor behind the build up of asset prices, the prudential regulatory policies can limit the credit flow and

\footnotetext{
${ }^{9}$ The bank-lending channel is particularly relevant for developing and emerging markets, given their underdeveloped financial markets where interest rates may not move to clear the market.
} 
Table 2. Causal relationship between changes in bank credit to private sector and changes in stock prices in India.

\begin{tabular}{lcc}
\hline Null Hypothesis: & F-Statistic & Prob. \\
\hline $\begin{array}{l}\text { Changes in bank credit to private sector do not Granger cause changes } \\
\text { in stock prices }\end{array}$ & 5.83 & 0.003 \\
$\begin{array}{l}\text { Changes in stock prices do not Granger cause changes in credit to } \\
\text { private sector }\end{array}$ & 7.03 & 0.001 \\
\hline
\end{tabular}

discourage banks' excessive exposure to specific assets/sectors. Stock price cycles in India appear to exhibit a synchronised movement with credit cycles, although the lead and lag relationships between them change over different phases of the cycle The Granger causality test between bank credit growth and changes in stock prices in India for the period 1996:Q1 to 2010:Q1 provides evidence of significant bi-directional causal relationship between them, as presented in Table 2. This implies that both credit boom and asset price booms reinforce each other - which is the typical feedback loop between credit and asset prices. This two-way causation could emanate from the fact that credit growth may directly finance purchases of stocks (which is limited in India) or indirectly push up asset prices by financing real estate activities, enhancing thereby the prospects of future earnings. As the value of stocks increases, the capacity to borrow against the shares as collateral also increases. This, however, is possible only to a limited extent in India.

\section{B. Monetary policy and housing price dynamics}

Housing wealth is considered to be an important component of the total household wealth and is regarded critical to explaining the demand behaviour in the advanced economies during the business cycles. Realisation of the asset appreciation through refinancing of mortgage makes the demand impact particularly strong, unlike in India where such refinancing of mortgage is mostly absent. As supply of housing is relatively inelastic in the short run, demand pressures may lead to disproportionate increase in prices. Further, speculative demand in a situation of inelastic short run supply may lead to build up of bubbles. An important link from monetary policy to asset prices is through the interest rate, which can influence the cost of mortgage debt and the demand for housing credit. ${ }^{10}$

\footnotetext{
${ }^{10}$ In advanced economies such as Japan, property prices were historically significantly responsive to real interest rate changes.
} 
Figure 1. Movement of stock prices and revenues from duties on housing in India.

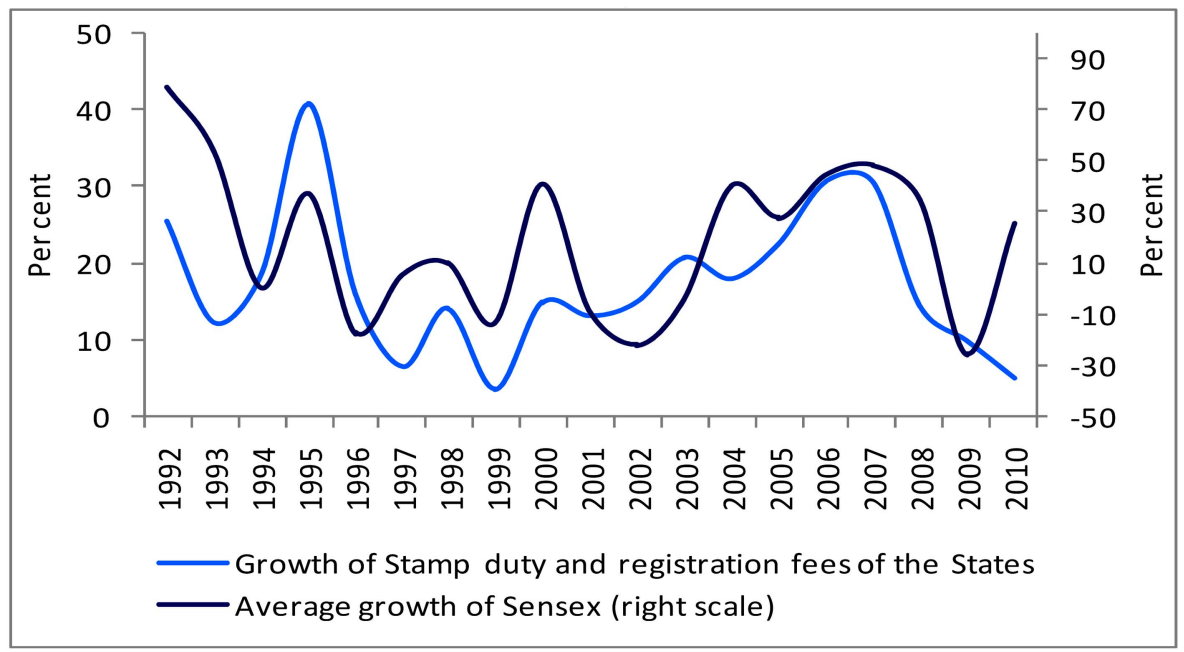

The changes in interest rates also signal possible changes in valuation of assets. Monetary policy is considered to influence the long-term cost of borrowing, which is relevant for the debt-financed housing demand. A tightening of interest rates may raise the cost of borrowing for households to finance such contractual debt and hence may lead to a decline in the demand, which in turn could lead to a downward pressure on prices.

Given the lack of data on housing wealth in India and the absence of a reasonable time series data even on housing prices, the house price behaviour has to be studied using a number of proxy indicators. ${ }^{11}$ Stamp duties and registration fees collected by the State governments could shed some light on the house price behaviour in India because these should move in tandem with house price. ${ }^{12}$ As

\footnotetext{
${ }^{11}$ Housing wealth data for India are not available. On housing prices, which could trace the changes in the housing wealth, time series data are not available. The National Housing Bank (NHB) provides data on NHB Residential Index starting from 2008 but these data have two limitations: first, the data are available with only half yearly frequency and come with a significant time lag, second, the indices are provided only for a number of major cities and no all India index is computed. The Reserve Bank of India has also started compiling house price index recently. However, the index is available only since the second quarter of 2003 and is compiled only for Mumbai, which has been extended to few more cities since 2009. Thus, there is a lack of time series data on an aggregate housing price index for India. ${ }^{12}$ It could be argued that registration fees may not reflect the true movement in house price as the actual market value of the house could be understated with a view to partly avoid the stamp duties and registration fees. For empirical analysis, given the data constraints, one could assume that the extent of under reporting of the market value of the residential properties for registration purposes has a systematic pattern over time and thus, could still capture the broad trends in residential property prices.
} 
Figure 2. (a) Price movement of realty sector in India.

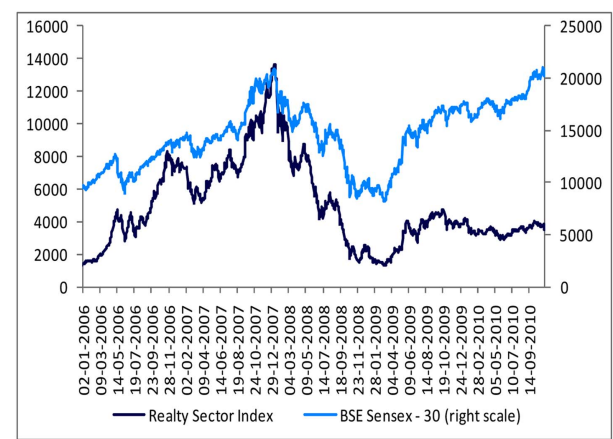

Figure 2. (B) Movement of Mumbai House Price Index.

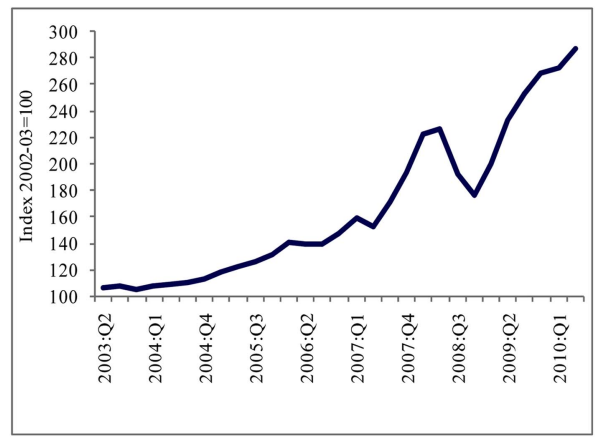

evident from Fig. 1, the movement of stock prices and revenues from stamp duties and registration fees on housing tend to follow a systematic relationship; they seem to suggest a broad underlying asset price cycle with occasional deviations across asset class. The recent boom-bust cycle in asset prices in India is evident from the inverted U-shape pattern for the period 2003 to 2010.

Equity prices of the real estate firms listed in the stock exchanges also provide some information about the price behaviour in the housing sector. The stock prices of the realty sector attained a peak at the end of 2007 and there was a substantial collapse following the financial market shocks from the global financial crisis (Fig. 2a). Although the broader index of stock prices (BSE Sensex) has returned closer to the pre-crisis level, the realty stock prices tend to remain sluggish. This recent behaviour of the realty sector stock price index seems to lag behind the extent of increase seen in the National Housing Bank and RBI housing prices indices (Fig. 2b).

Growth in bank credit to the construction sector (proxy for real estate) in India exhibited a clear cyclical pattern during the period 2000-01 to 2009-10 (Fig. 3). 
Figure 3. Bank credit to construction sector in India.

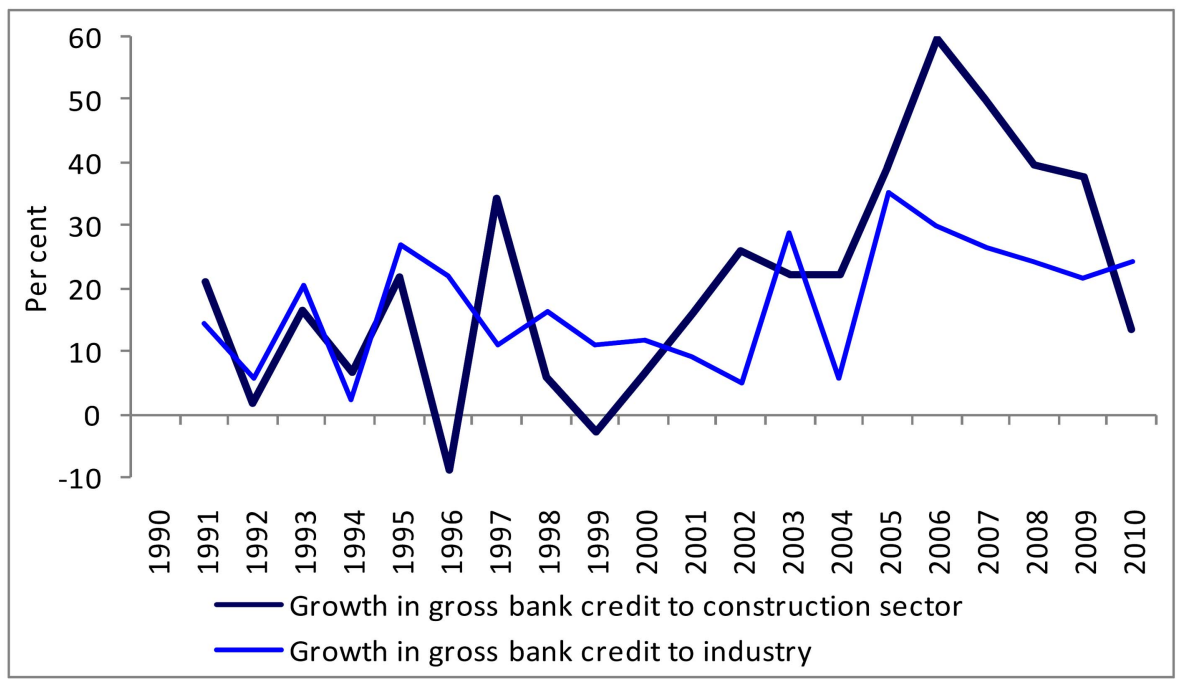

Reflecting the house price boom, growth in bank credit to the construction sector was significantly above the overall growth of bank credit to industry. It may, however, be mentioned that as part of prudential regulations in India, bank credit to sectors such as real estate and stock markets is regulated in relation to expansion in the banks' overall asset portfolio. Secondly, the banks' credit exposures to real estate and stock markets attract higher capital requirements. ${ }^{13}$ In respect of residential housing, however, credit is given preferential treatment in terms its classification as a priority sector loan including lower capital requirements. In a situation where housing asset values tend to witness a secular growth, banks may have an incentive to expand credit to residential housing segment where credit risks are perceived to be relatively low since such loans are backed by collaterals whose values are expected to rise in future.

\footnotetext{
${ }^{13}$ Risk weight on banks' exposure to the commercial real estate (CRE) and capital market were increased from 100 per cent to 125 per cent in July 2005. Given the continued rapid expansion in credit to the commercial real estate sector, the risk weight on exposure to this sector was increased to 150 per cent in May 2006. The general provisioning requirement on standard advances in specific sectors, i.e., personal loans, loans and advances qualifying as capital market exposures, residential housing loans beyond Rs.20 lakh and commercial real estate loans was also increased from 0.4 per cent to one per cent in April 2006 and further to two per cent on January 31, 2007. These norms were relaxed to deal with the slowdown i growth that resulted from the global financial crisis. In October 2010, these norms were tightened again in response to rising asset prices.
} 
Table 2. Causal relationship between housing loans and interest rates.

\begin{tabular}{lcc}
\hline Null Hypothesis: & F-Statistic & Prob \\
\hline TB91 does not Granger cause dLBC_hsg & 3.01 & 0.06 \\
dLBC_hsg does not Granger cause TB91 & 0.40 & 0.67 \\
10yGsec does not Granger cause dLBC_hsg & 2.93 & 0.00 \\
dLBC_hsg does not Granger cause 10yGsec & 0.48 & 0.90 \\
\hline
\end{tabular}

Another important dimension of the role of monetary policy in affecting house prices is the impact of interest rate on the demand for bank credit by the housing sector, which in turn, affects house prices with a lag. The Granger causality test for the period 2002:4 to 2010:6 suggests that short-term interest rate (TB91) Granger cause changes in bank credit to the housing sector (dLBC_hsg) (Table 2). A significant unidirectional causality is also observed from the long-term interest rates (10yGsec) to the demand for credit to the housing sector, though with longer lags.

The Granger causality analysis between house prices for the period 2003:Q2 to 2010:Q2, proxied by housing prices for the Mumbai city (dLHPI), stock prices (dLSENSEX_SA) and short-term interest rates measured by the weighted average call money rates (RCALL) provides some insights about the asset price dynamics (Table 3). Interest rate changes seem to Granger cause changes in house prices. This finding may be relevant from the viewpoint of effectiveness of monetary policy in influencing house prices in India. While asset prices may respond to changes in interest rates, the policy interest rates would have been changed in response to assessment about the growth and inflation outlook. Constructing a counterfactual to study the impact of monetary policy changes on asset prices, thus, could be extremely difficult. This is primarily the reason as to why the Reserve Bank has abstained from using interest rate instrument with the sole aim of influencing asset prices. Although Joshi (2006) found that housing prices in India are significantly much more sensitive to interest rate changes than to credit supply,

Table 3. Causal relationship between house prices, stock prices and short-term interest rate.

\begin{tabular}{lcc}
\hline Null Hypothesis: & F-Statistic & Prob. \\
\hline d(LSENSEX_SA) does not Granger Cause d(LHPI) & 0.62 & 0.55 \\
d(LHPI) does not Granger Cause d(LSENSEX_SA) & 7.66 & 0.00 \\
RCALL does not Granger Cause d(LHPI) & 3.31 & 0.05 \\
d(LHPI) does not Granger Cause RCALL & 0.41 & 0.67 \\
\hline
\end{tabular}


the findings were based on a relatively short sample.

\section{Empirical results from SVAR model}

To examine the dynamic interactions among all the macroeconomic variables and asset prices, a structural vector auto regression (SVAR) model was estimated using the following variables: real income (GDP), price level (WPI), real interest rate (call money rates minus GDP deflator), real bank credit (stock of non-food bank credit deflated by GDP deflator), real stock prices (Sensex deflated by GDP deflator), and real exchange rate (6-currency REER index). The Gibbs sampling technique was applied to the VAR model, with standard Minnesota priors. The priors are particularly useful to estimate models where the sample period in not adequately long. The standard structural system can be considered of the following linear and stochastic dynamic form:

$$
A_{0} y_{t}=B(L) y_{t-i}+\varepsilon_{t} \text { with } i=1, \ldots \ldots \ldots n
$$

The following theoretically plausible restrictions are imposed on the structure of the model to identify various structural shocks.

$$
\left[\begin{array}{c}
e_{y} \\
e_{p} \\
e_{r} \\
e_{c} \\
e_{s} \\
e_{x}
\end{array}\right]=\left[\begin{array}{lllllc}
1 & 0 & 0 & 0 & 0 & 0 \\
\alpha 21 & 1 & 0 & 0 & 0 & 0 \\
0 & \alpha 32 & 1 & 0 & 0 & \alpha 36 \\
\alpha 41 & \alpha 42 & \alpha 43 & 1 & 0 & 0 \\
\alpha 51 & \alpha 52 & \alpha 53 & \alpha 54 & 1 & 0 \\
\alpha 61 & \alpha 62 & \alpha 63 & \alpha 64 & \alpha 65 & 1
\end{array}\right]=\left[\begin{array}{c}
\varepsilon_{y} \\
\varepsilon_{p} \\
\varepsilon_{r} \\
\varepsilon_{c} \\
\varepsilon_{s} \\
\varepsilon_{x}
\end{array}\right]
$$

The model has the standard assumption that real income shocks are most exogenous and are not instantaneously affected by other macroeconomic aggregates in the model, therefore, all coefficients in the matrix are restricted to zero. Price behaviour is impacted by the aggregate demand shocks contemporaneously but not by other shocks. The monetary policy reaction function has the restriction that monetary policy does not contemporaneously respond to output shocks. This restriction is based on the argument that often the information on output is available to monetary authorities with a time lag. The reaction function, however, assumes contemporaneous reaction of monetary policy to price changes and the 
exchange rate movements. Exchange rate enters the monetary policy reaction function as the central bank also attempts to maintain stability of foreign exchange market - a typical emerging market phenomenon. An important dimension of the asset price dynamics captured in this model is the feedback between bank credit and asset prices. Credit demand is contemporaneously affected by the real income shocks, supply shocks and the monetary policy shocks.

Asset prices, measured in terms of stock market prices, are contemporaneously affected by the fundamental as well as the non-fundamental factors, except the exchange rate. Asset price is contemporaneously affected by the credit shocks in

Figure 4. Impulse responses of stock prices to various shocks.
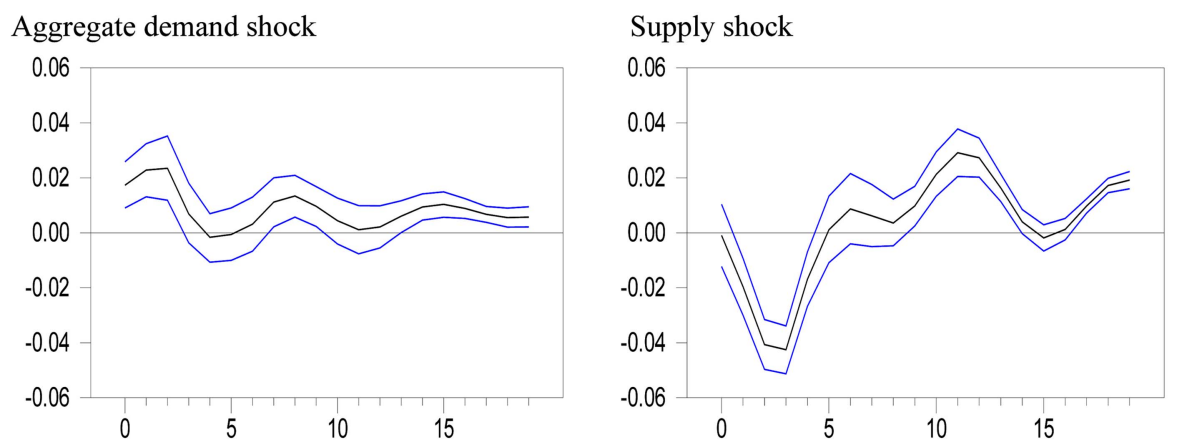

Monetary policy shock

Credit market shock
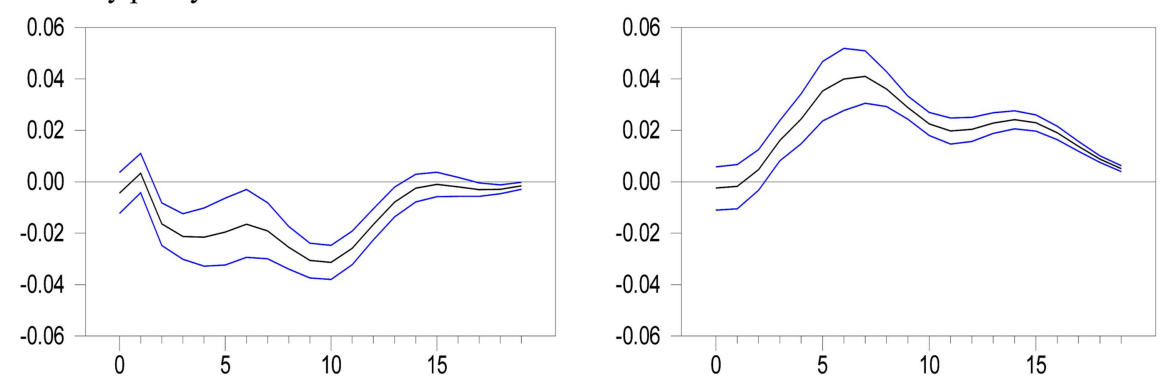

Stock market shock

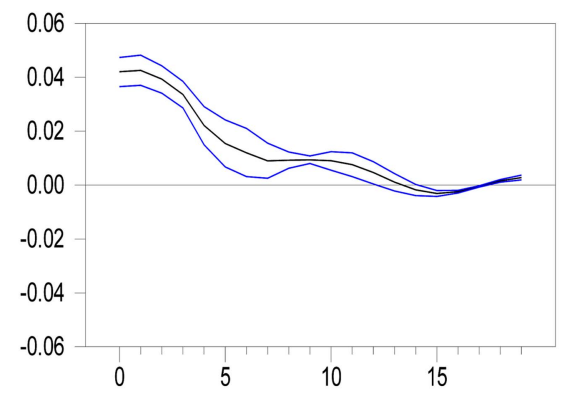

Exchnage rate shock

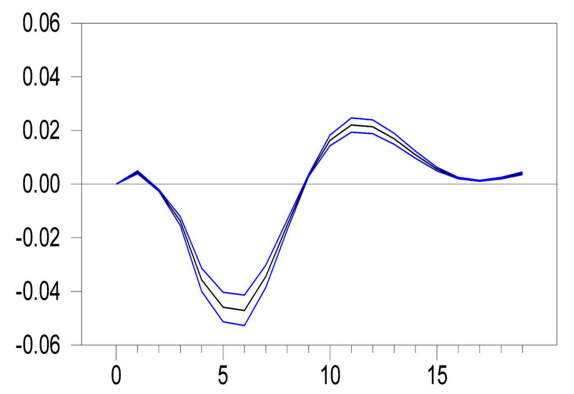


the model as the underlying dynamics is that most asset price bubbles are associated with excessive credit growth. The standard practice in the VAR literature on monetary policy and exchange rate interaction is to place the exchange rate last in the ordering while the exchange rate is allowed to react simultaneously to all shocks. The exchange rate can react instantaneously to all shocks, even though the presence of nominal rigidities may lead to only gradual pass through of exchange rate shocks to macroeconomic variables. This should provide enough restriction to identify the system, thereby allowing for the use of the non-recursive decomposition.

The model is now uniquely identified and the shocks are orthogonal (uncorrelated). Quarterly seasonally adjusted data from 1996:Q2 to 20010:Q2 are used. Although some variables appear to be non-stationary, the VAR model is estimated in levels following Sims et al. (1990) that a VAR model in levels may incur some loss in estimators' efficiency but not the consistency. The objective of estimating a VAR model in levels is to examine the relationship among variables. The optimal lag length based on various criteria (viz., LR test statistic, Akaike information criterion, Schwarz information criterion and Hannan-Quinn information criterion) appeared to be three quarters.

The estimated structural VAR model explains various channels through which asset prices may be influenced, which are presented in Fig. 4. Aggregate demand shocks (i.e., an increase in aggregate demand) lead to an increase in stock prices in the short run and the impact fizzles out in the medium to long run. Favourable aggregate demand shocks signal an improvement in the fundamentals of the economy and raise expectations of the future earnings growth in the stock market. An adverse supply shock that causes sudden changes in relative prices, leads to significant moderation in stock prices in the short to medium run. The asset price channel of monetary policy is found to be strong. A monetary policy shock causes significant fluctuations in equity prices. Monetary policy works with variable lags. The impulse response functions exhibit that monetary policy tightening leads to a slow but significant moderation in stock price changes over the medium to long run. In the framework of the life cycle hypothesis of consumption, when stock prices decrease, consumers' wealth also decreases and they spend less on consumption. Thus, monetary policy could affect demand through the asset price channel. In India, on an average about 6 per cent of total financial assets of households are held in the form of equity.

An important issue of concern to the policy makers is how asset price shocks 
propagate to the rest of the economy and with what lags they impact various macroeconomic aggregates. The estimated structural VAR model exhibits that stock price shocks affect output with some lag over the medium-term, though with no significant long run impact (Appendix 1). The impact on output could be through the typical wealth effect and balance sheet channels that cause changes in consumption and investment. An adverse output shock, which may be the result of negative shock to asset prices, triggers an expansionary monetary policy response in terms of lower interest rate in the short run. This corroborates the indirect role of monetary policy relative to asset prices, i.e., through the impact on output. Asset price shocks do not seem have a significant direct impact on the price level. Shocks from stock prices explain only marginal fluctuations in the overall price level over medium to long run. This suggests no need for even indirect monetary policy response to asset price developments, unlike the impact observed through output.

Stock price shocks also do not seem to lead to any noticeable changes in interest rates in the short run. It suggests that monetary policy does not respond to asset prices. This could also be because of the muted impact of stock price shocks on inflation. Favourable stock price shocks tend to cause increase in the demand for bank credit with a lag over the medium-term. In fact, by the end of eight quarters, stock price shocks explain about 10 per cent of the fluctuations in real demand for credit. The most significant impact of stock price shocks is on the real exchange rate, which possibly works through changes in capital flows. Higher stock prices change the return differentials for foreign investors, making investment in the Indian markets more attractive, which in turn lead to higher inflows and hence appreciation of the real exchange rate in the short run. This effect, however, moderates over medium to long run.

The above findings suggest that though the direct impact of asset price shocks on goods prices is not significant, they may still be of interest to the central bank from the standpoint of their impact on credit demand, output and the exchange rate. Thus, monetary policy may respond to asset prices only indirectly, for which, however, clearer identification of the influence of asset price changes on inflation, growth or exchange rate would be important. Asset prices appearing to be sensitive to monetary policy changes do not provide a strong case for deploying monetary policy to counter asset price movements. Relying on the asset price channel to achieve the ultimate policy goals of growth and price stability could be too risky a proposition to be ventured. Thus, interest rate channel should remain the prime focus of monetary policy, even if asset prices may respond to changes in monetary 
policy, which in turn may influence the ultimate goal variables that the monetary policy aims to achieve. Asset prices as such should not become an intermediate objective of monetary policy.

The response of stock prices to credit market shocks validates the presumed role of credit expansion in contributing to the asset price bubbles. ${ }^{14}$ A comparative assessment of the impulse response functions reveals that monetary policy tightening leads to a moderation in credit demand over the medium-term, given the usual lags in the impact of monetary policy (Appendix 1). The tightening of policy interest rates, thus, impacts the stock prices, as financing the leverage in the markets turns costlier. ${ }^{15}$ The impulse responses exhibit that a positive shock to bank credit causes significant increase in equity prices over medium to long run. The credit market shock at the same time causes significant variations in real output. Thus, the asset price dynamics becomes complicated as the positive credit shocks lead to simultaneous increase in both output and asset prices. From the perspective of a monetary policy response, it becomes difficult to segregate the part of asset price increase that may be caused by improvement in fundamentals from that led by speculative credit flows to asset markets.

The stock market shock, measured in terms of lagged impact of the stock prices, could reflect composite impact of backward-looking investor behaviour, overreaction by agents to news about the fundamentals, impact of sudden surges in portfolio inflows and the herd behaviour/animal spirits. These shocks are most dominant in causing fluctuations in stock prices in the short run but their impact peters-off at a rapid pace. Another important channel through which asset prices are impacted is the exchange rate channel. A positive shock to real exchange rate, signifying the adverse external competitiveness shock, results in significant moderation in stock prices with a lag, consistent with lags in exchange rate transmission to macroeconomic aggregates. The impact, however, does not seem to be persistent.

The results of the decomposition of fluctuations in stock prices caused by

\footnotetext{
${ }^{14}$ Variations in bank credit are an important channel of monetary policy transmission mechanism even for central banks that rely on interest rates to convey their policy stance. Modulations in policy interest rates by the central bank influence credit market conditions which reinforce the effects of the traditional interest rate channel of monetary transmission.

${ }^{15}$ The impact of credit channel on asset prices can also work through changes in market perception. As credit conditions are tightened, the perception about the overheating of the economy may get strengthened and accordingly the stock prices would be adversely affected.
} 
Table 4. Decomposition of fluctuation caused in stock prices.

$(\%)$

\begin{tabular}{ccccccc}
\hline Quarters & $\begin{array}{c}\text { Demand } \\
\text { shock }\end{array}$ & $\begin{array}{c}\text { Supply } \\
\text { shock }\end{array}$ & $\begin{array}{c}\text { Monetary } \\
\text { policy shock }\end{array}$ & $\begin{array}{c}\text { Credit market } \\
\text { shock }\end{array}$ & $\begin{array}{c}\text { Asset price } \\
\text { shock }\end{array}$ & $\begin{array}{c}\text { Exchange } \\
\text { rate shock }\end{array}$ \\
\hline 1 & 14.1 & 0.0 & 1.1 & 0.5 & 84.3 & 0.0 \\
4 & 10.4 & 26.9 & 6.4 & 2.1 & 52.4 & 1.8 \\
8 & 6.1 & 13.3 & 8.4 & 18.8 & 27.0 & 26.5 \\
12 & 7.3 & 13.4 & 14.9 & 21.5 & 20.6 & 22.2 \\
16 & 7.4 & 14.3 & 14.1 & 23.8 & 18.4 & 22.0 \\
20 & 7.7 & 15.3 & 13.6 & 24.4 & 17.8 & 21.2 \\
\hline
\end{tabular}

various macroeconomic shocks are presented in Table 4. Although the asset price shock explains the predominant part of variations in stock prices in the short run, it is the credit demand shock that explains the largest proportion of variations in asset prices over the medium to long run. The aggregate demand and supply shocks tend to have short to medium-term impact on stock prices. The variance decomposition analysis of fluctuations in credit demand also reveals that aggregate demand shocks explain significant variation in real credit demand, which in turn, might be impacting on the stock price movements given the causal relationship between bank credit and stock prices (Appendix 2). The real exchange rate shock turns significant over the medium to long run in explaining fluctuations in stock prices in India. The role of exchange rate in affecting asset prices could emanate from

Figure 6. Historical decomposition of fluctuations in real stock prices explained by various macroeconomic shocks.

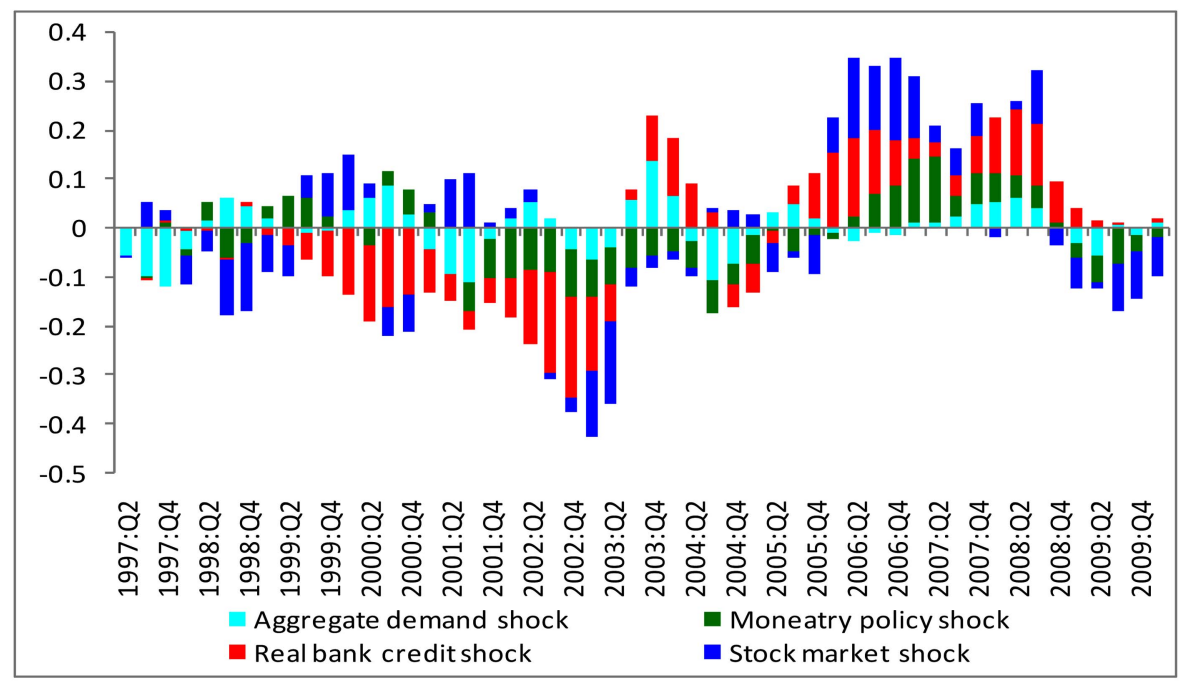


changes in relative attractiveness of returns to foreign capital in the stock markets in the short run due to nominal appreciation of the rupee and a loss of overall external competitiveness over the medium to long run, which may adversely affect the growth outlook and hence dampen stock prices.

The contributions of various shocks to asset price movement in India could be gleaned from the historical decomposition of the fluctuations in stock prices. It is evident from Fig. 6 that booms in stock prices since the mid-2000s were, on an average, dominated by real credit and stock market shocks. The stock market residual shocks capture the composite impact of a host of factors including the news about fundamentals and sudden changes in the market sentiments driven by foreign institutional investors as well as the unanticipated domestic shocks. Although the contribution of the monetary policy shocks during the early phase of the recent asset cycle boom appeared to be significant, it tapered-off subsequently.

\section{Conclusion}

In the post-global crisis period there has been an increasing emphasis on the need to explore the scope of monetary policy responding directly to asset price developments to be able to promote financial stability. This renewed interest in the role of monetary policy in stabilising asset price cycles has compelled policy makers to have a re-look at the pre-crisis consensus that seemed to favour a handsoff approach to asset price but manage the consequences of both booms and busts in asset price cycles. The extensive debate after the global crisis does not seem to suggest that the pre-crisis consensus was blatantly fallacious. Alternative instruments at the disposal of central bank, namely micro and macro-prudential tools, could be superior relative to the interest rate instrument, both in terms of effectiveness and minimising the overall costs for the economy. Monetary policy as a macroeconomic policy tool can ensure an environment in which prudential regulation could become somewhat more effective.

In India, despite the limited risks from asset price cycles to macro-financial conditions relative to the advanced economies, much greater reference to asset prices is being made in the context of monetary policy. The concerns relating to surges in capital flows fuelling asset prices has also provided another dimension to the debate on the dynamics between capital flows, asset prices and monetary policy. The Reserve Bank has used in the past both micro and macro-prudential measures to limit the risks to financial stability from asset price cycles. It, however, 
has justifiably refrained from using policy interest rates with the specific intention of influencing asset prices. This paper provides empirical evidence to explain the appropriateness of such an approach and highlights that the same approach may have to continue. Expected impact of asset price trends on inflation and output, however, needs to be assessed regularly so that the scope for indirect response of monetary policy to asset price shocks could be integrated to the monetary policy framework. The macroeconomic analysis for the conduct of monetary policy may be relevant for designing the structure and even for deciding on the timing of macro-prudential measures, but the monetary policy itself, which already caters to multiple objectives, should not be assigned any explicit direct role to stabilise asset prices. In this context, any policy that aims at limiting the overall pace of credit growth may have to be driven by developments such as either economic overheating or persistent high inflation, but not the perception of an asset price bubble. Similarly, if an accommodative monetary policy stance has to be sustained for a prolonged period in response to an economic slowdown or a recession, the fear of such a stance leading to asset price inflation should not trigger hasty tightening of monetary policy. For the purpose of clarity, sector specific limits on the flow of credit to asset price sensitive sectors, or even caps on direct and indirect exposure of the banking system to asset price cycles should be seen purely as prudential measures, which are different from monetary policy measures.

The empirical analysis for India exhibits that while interest rate changes cause changes in stock prices, the reverse causality does not hold. This validates the point that monetary policy in India does not respond to asset prices, but the asset price channel of monetary policy exits. Evidence of a significant bi-directional causal relationship between credit growth and asset price trends does not provide any unambiguous result about the role of credit in asset price bubbles. This is so because of the role of a common factor; i.e. strong GDP/IIP growth coinciding with high credit growth, and the former driving the asset prices up.

Regarding housing assets, given the absence of a reasonably long time series data on house prices, this paper used a number of proxy variables. The movement of stock prices and collection of "stamp duties and registration fees" relating to housing tend to follow a symmetric relationship, indicating the possibility of a broad-based asset price cycle. The housing credit demand in India appears to be sensitive to interest rate movements, which though does not validate an explicit role for monetary policy in influencing housing prices. This is because the impulse response functions reveal that monetary policy tightening leads to a moderation in 
credit demand over the medium-term, given the usual lags in the impact of monetary policy, which in turn gives rise to lower real output. Thus, any asset price objective attempted to be achieved through monetary policy actions would involve sacrifice of growth. Given the possibility of an adverse feedback loop, where falling asset prices and contraction in output could intensify in a spiral, direct use of monetary policy may better be avoided. Moreover, asset price dynamics could be difficult to decipher for meaningful use in the conduct of monetary policy. For example, an increase in the flow of credit in the VAR model seems to lead to increase in both output and asset prices. It could be, however, particularly difficult to segregate the part of asset prices increase that might have been caused by improvement in fundamentals from the part led by speculative credit flows to asset markets. This ambiguity suggests why countercyclical regulatory policies to counter asset price bubbles could be more appropriate relative to direct use of monetary policy.

Received 18 November 2010, Revised 12 February 2012, Accepted 14 February 2012

\section{References}

Robert B. Barsky and J. Bradford DeLong. (1993), "Why Does the Stock Market Fluctuate?" Quarterly Journal of Economics, 108(2), pp. 291-312.

Bean, Charles. (2003), "Asset Prices, Financial Imbalances and Monetary Policy: Are Inflation Targets Enough?" BIS Working Paper No.140, September.

Bernanke B S and M Gertler. (1999), "Monetary policy and asset volatility", Federal Reserve Bank of Kansas City Economic Review, 84(4), pp 17-52.

Bernanke, Ben S., Mark Gertler and Simon Gilchrist. (1999), "The financial accelerator in a quantitative business cycle framework," in J. B. Taylor and M. Woodford (ed.), Handbook of Macroeconomics, edition 1, volume 1, chapter 21, pp. 1341-1393, Elsevier.

Bernanke, B. S. and M. Gertler. (2001), "Should Central Banks Respond to Movements in Asset Prices?" American Economic Review, Vol. 91(2), pp. 253-257.

Blinder, Allan S. and R. Reis. (2005), "Understanding the Greenspan standard", paper presented at the symposium The Greenspan era: lessons for the future, sponsored by the Federal Reserve Bank of Kansas City, Jackson Hole, Wyoming, 25-27 August. Blinder, Allan S. (2008), "Two Bubbles, Two Paths", The New York Times, June 15.

Bordo, M. D., M. J. Dueker and D. C. Wheelock. (2002), “Aggregate price shocks and financial stability: a historical analysis", Economic Inquiry, 40(4), pp. 521-38, October.

Bordo M. D., M. J. Dueker and D. C. Wheelock. (2003): “Aggregate price shocks and 
financial stability: the United Kingdom, 1796-1999", Explorations in Economic History, 40(2), pp. 143-69, April.

Bordo M D and D C Wheelock. (2004), "Monetary policy and asset prices: a look back at past U.S. stock market booms", Federal Reserve Bank of St Louis Review, 86(6), pp 19-44, November/December.

Filardo, A. J. (2000), "Monetary policy and asset prices," Federal Reserve of Kansas City Economic Review, 3rd quarter, pp. 11-37.

Filardo, A. J. (2004), "Monetary Policy and Asset Price Bubbles: Calibrating the Monetary Policy Trade-offs", BIS Working Papers, No. 155, June.

Froot, K. and M. Obstfeld. (1991), "Intrinsic bubbles: the case of stock prices", The American Economic Review, December.

Garber, P. (2000), Famous first bubbles, Cambridge: MIT Press.

Goodhart, C. and B. Hofmann. (2000), "Financial Variables and the Conduct of monetary Policy,” Sveriges Riksbank Working Paper No. 112.

Gramlich, Edward. (2001), "Asset Prices and Monetary Policy," Remarks at the New Technologies and Monetary Policy International Symposium. Bank of France, November 30.

Greenspan, Alan. (2002), Opening remarks in Rethinking stabilization policy, a symposium sponsored by the Federal Reserve Bank of Kansas City, Jackson Hole, Wyoming, 29-31 August.

Gruen, D., M. Plumb and A. Stone. (2005), "How Should Monetary Policy Respond to Asset-Price Bubbles?" International Journal of Central Banking, 1(3): 1-32.

International Monetary Fund. (2006), "Asset Prices and the Business Cycle”, World Economic Outlook, IMF, Washington, DC.

International Monetary Fund. (2009), "Lessons from the Global Crisis for Macroeconomic Policy", Research Department, IMF, Washington, DC, February 19.

Issing, Otmar. (2002), "Monetary policy in a changing economic environment," Proceedings, Federal Reserve Bank of Kansas City, pages 183-205.

Issing, Omar. (2009), "In search of monetary stability: the evolution of monetary policy", BIS Working Paper no. 273.

Joshi, Himanshu. (2006), "Identifying Asset Price Bubbles in the Housing Market in India - Preliminary Evidence”, Reserve Bank of India Occasional Papers Vol. 27, No. 1 and 2.

Kohn, D.L. (2008), "Monetary policy and asset prices revisited," Speech at the Cato Institute's $26^{\text {th }}$ Annual Monetary Policy Conference, Washington, November 19.

Kuttner, Kenneth and Patricia Mosser. (2002), “The Monetary Transmission Mechanism: Some Answers and Further Questions," Federal Reserve Bank New York Economic Policy Review 8 (May), pp. 15-26.

Ludvigson, Sydney, Charles Steindel, and Martin Lettau. (2002), "Monetary Policy Transmission through the Consumption-Wealth Channel," Federal Reserve Bank New York Economic Policy Review 8 (May), pp. 117-133. 
Mishkin, Frederic S. (2008), "How Should We Respond to Asset Price Bubbles?", the Wharton Financial Institutions Center and Oliver Wyman Institute's Annual Financial Risk Roundtable, Philadelphia, Pennsylvania, May 15.

Mishkin, Frederic S. and White, Eugene N. (2002), "U.S. Stock Market Crashes and Their Aftermath: Implications for Monetary Policy", Asset Price Bubbles Conference, Federal Reserve Bank of Chicago and The World Bank, Chicago, April 23.

Orphanides, Athanasios. (2010), "Monetary Policy Lessons from the Crisis", CEPR Discussion Paper No. 7891, June.

Papademos, Lucas. (2009), "Monetary Policy and the 'Great Crisis': Lessons and Challenges." Speech by Vice President of the ECB at the 37th Economics Conference "Beyond the Crisis: Economic Policy in a New Macroeconomic Environment" organised by the Österreichische Nationalbank, Vienna, May 14.

Roubini, Nouriel. (2006), "Why Central Banks Should Burst Bubbles", International Finance, 9(1), pp. 87-107, Spring.

Rudebusch, G.D. (2005), "Monetary policy and asset price bubbles," FRBSF Economic Letter, 2005-18, August.

Saxton, Jim. (2003), Monetary Policy and Asset Prices, Joint Economic Committee, US Congress, April.

Sims, C., J.H. Stock and M.W. Watson. (1990), "Inference in linear time series models with some unit roots," Econometrica, 58, pp. 113-144.

Stock, James H. and Mark W. Watson. (2001), "Forecasting Output and Inflation: The Role of Asset Prices," NBER Working Papers 8180, National Bureau of Economic Research.

Trichet, Jean-Claude. (2009), "After the Crisis", Keynote speech at the 19th Frankfurt European Banking Congress: Frankfurt am Main, Alte Oper, 20 November 2009.

Tatom, John A. (2002), "Stock Prices, Inflation and Monetary Policy," Paper presented at the National Association of Business Economics Meetings, September 29-October 1. 


\section{Appendix}

Appendix 1. Impulse response of macroeconomic variables to various shocks.
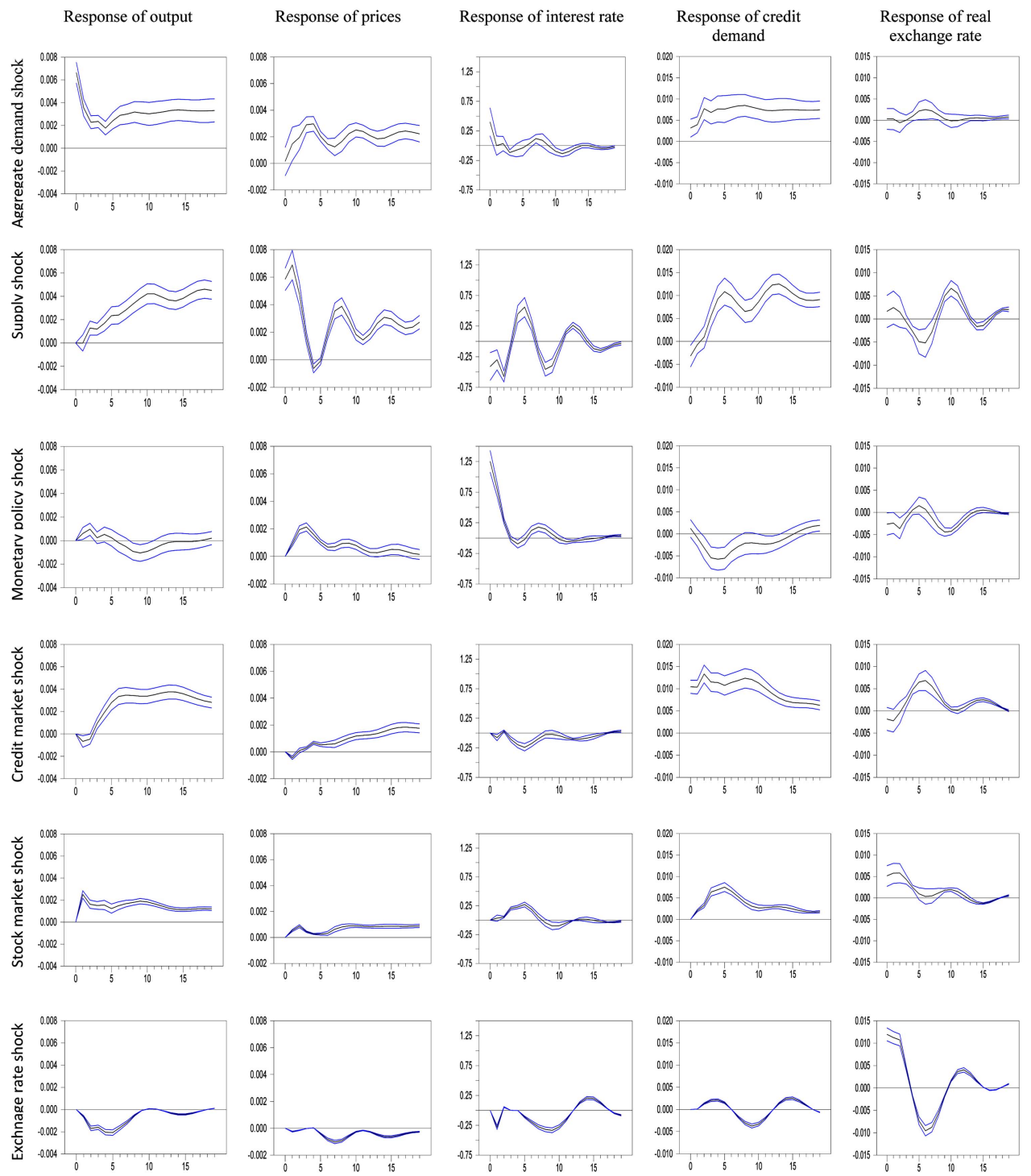
Appendix 2. Decomposition of fluctuation caused in various macroeconomic variables (\%).

\begin{tabular}{|c|c|c|c|c|c|c|}
\hline Quarters & $\begin{array}{c}\text { Demand } \\
\text { shock }\end{array}$ & $\begin{array}{l}\text { Supply } \\
\text { shock }\end{array}$ & $\begin{array}{c}\text { Monetary } \\
\text { policy shock }\end{array}$ & $\begin{array}{c}\text { Credit market } \\
\text { shock }\end{array}$ & $\begin{array}{l}\text { Asset price } \\
\text { shock }\end{array}$ & $\begin{array}{l}\text { Exchange } \\
\text { rate shock }\end{array}$ \\
\hline \multicolumn{7}{|c|}{ Aggregate output } \\
\hline 1 & 100.0 & 0.0 & 0.0 & 0.0 & 0.0 & 0.0 \\
\hline 4 & 71.3 & 3.4 & 1.6 & 1.9 & 14.3 & 7.5 \\
\hline 8 & 46.5 & 12.2 & 1.1 & 18.6 & 11.2 & 10.3 \\
\hline 12 & 38.5 & 22.4 & 1.5 & 22.4 & 9.7 & 5.5 \\
\hline 16 & 36.0 & 25.5 & 1.1 & 25.6 & 7.9 & 3.9 \\
\hline 20 & 34.5 & 30.0 & 0.8 & 24.8 & 6.9 & 3.0 \\
\hline \multicolumn{7}{|l|}{ Price level } \\
\hline 1 & 1.2 & 98.8 & 0.0 & 0.0 & 0.0 & 0.0 \\
\hline 4 & 9.5 & 81.4 & 7.7 & 0.2 & 1.1 & 0.1 \\
\hline 8 & 14.8 & 72.6 & 9.0 & 1.0 & 1.3 & 1.3 \\
\hline 12 & 19.2 & 66.0 & 7.9 & 2.8 & 2.4 & 1.6 \\
\hline 16 & 21.3 & 62.1 & 6.4 & 5.4 & 3.0 & 1.7 \\
\hline 20 & 24.1 & 57.4 & 5.4 & 8.2 & 3.4 & 1.6 \\
\hline \multicolumn{7}{|c|}{ Real short-term interest rate } \\
\hline 1 & 0.0 & 10.4 & 89.6 & 0.0 & 0.0 & 0.0 \\
\hline 4 & 2.5 & 19.0 & 73.6 & 0.6 & 1.5 & 2.8 \\
\hline 8 & 1.9 & 27.9 & 56.0 & 3.8 & 5.2 & 5.2 \\
\hline 12 & 2.1 & 31.1 & 47.7 & 3.4 & 4.8 & 11.0 \\
\hline 16 & 2.1 & 31.6 & 45.5 & 3.8 & 4.6 & 12.4 \\
\hline 20 & 2.2 & 31.8 & 44.9 & 3.8 & 4.6 & 12.7 \\
\hline \multicolumn{7}{|c|}{ Real bank credit } \\
\hline 1 & 5.0 & 8.2 & 1.2 & 85.6 & 0.0 & 0.0 \\
\hline 4 & 20.1 & 5.1 & 5.4 & 61.8 & 7.0 & 0.8 \\
\hline 8 & 23.1 & 16.8 & 5.9 & 43.2 & 10.4 & 0.7 \\
\hline 12 & 24.2 & 18.4 & 4.5 & 43.2 & 8.0 & 1.6 \\
\hline 16 & 24.6 & 25.3 & 3.6 & 38.1 & 6.8 & 1.6 \\
\hline 20 & 25.4 & 27.5 & 3.3 & 36.1 & 6.2 & 1.5 \\
\hline \multicolumn{7}{|c|}{ Real exchange rate } \\
\hline 1 & 0.7 & 1.8 & 3.8 & 2.0 & 14.2 & 77.5 \\
\hline 4 & 0.5 & 2.3 & 4.9 & 2.2 & 19.4 & 70.7 \\
\hline 8 & 1.2 & 7.3 & 3.2 & 14.4 & 11.7 & 62.2 \\
\hline 12 & 2.0 & 13.4 & 7.1 & 12.8 & 10.3 & 54.5 \\
\hline 16 & 1.9 & 13.7 & 7.0 & 13.3 & 10.1 & 54.1 \\
\hline 20 & 2.1 & 14.1 & 6.9 & 13.6 & 10.0 & 53.3 \\
\hline
\end{tabular}

